\title{
Remembering Philippe Leuenberger
}

\author{
Ursula Ackermann-Liebrich ${ }^{1,2}$, Nicole Probst-Hensch ${ }^{1,2}$ and Thierry Rochat ${ }^{3}$, on \\ behalf of the national and international SAPALDIA team; and Jean William Fitting ${ }^{4}$ \\ and Laurent Nicod ${ }^{4}$, on behalf of the University Hospital of Lausanne
}

\author{
Affiliations: \\ ${ }^{1}$ Swiss Tropical and Public Health Institute, University of Basel, Switzerland. \\ ${ }^{2}$ University of Basel, Switzerland. \\ ${ }^{3}$ Service de pneumologie, Hôpital Universitaire de Genève (HUG), Genève, Switzerland. \\ ${ }^{4}$ Service de Pneumologie, Centre Hospitalier Universitaire Vaudois (CHUV), Lausanne, Switzerland.
}

Correspondence: Laurent Nicod, Service de Pneumologie, Centre Hospitalier Universitaire Vaudois (CHUV), Lausanne, $1011 \mathrm{CH}$, Switzerland. E-mail: laurent.nicoddachuv.ch

Philippe Leuenberger, pulmonologist, died on September 28, 2015. Switzerland and the international respiratory medicine community have lost an outstanding researcher, a scientific leader and a talented teacher. Those who had the privilege to work with him will remember a generous colleague with an unusual talent for integration and collaboration, and many of us will also remember a most reliable friend.

Philippe Leuenberger was born in 1944 and studied medicine at the University of Lausanne, where he graduated in 1969. His postgraduate training led him from a small rural hospital in St Loup to the University of Fribourg and then to Columbia University in New York. He thus acquired a strong background in physiology, but also an interest in pulmonary oncology and in the biology of alveolar macrophages. Back in Switzerland, he was soon appointed as full professor and director of the pulmonary department at the University Hospital of Lausanne, a position he held until 2006 when disease forced him into early retirement.

In 1988 the Swiss Respiratory Society asked him to take responsibility for a national study on the influence of air pollution on respiratory health, in collaboration with epidemiologists from the University of Basel under the leadership of Ursula Ackermann-Liebrich. This was the start of an unusual collaboration between clinical and epidemiological researchers in a national study under the now well-known name SAPALDIA (Swiss Study on Air Pollution and Lung Diseases in Adults). This project became a success story, with a cohort that has now been followed for 24 years, integrating the only nationwide population-based biobank, and involving collaborators from all over Switzerland, with long-term support from the Swiss National Science Foundation as well as from other local, regional, national and international funding bodies. The collaborative spirit of Philippe Leuenberger, his effort to integrate clinical thinking into epidemiological research and thus to develop new synergies, were unique at the time and are probably still unusual even today. His vision stimulated a form of interdisciplinary collaboration far beyond the individual fields of activity of all those involved in the SAPALDIA team. Many of the collaborators from the very beginning are still actively involved in this ever growing enterprise. There were many obstacles to overcome. Aside from the continuous battle to find the necessary funding, the vigorous fight with the tobacco industry after Philippe Leuenberger's first SAPALDIA publication on the effects of passive smoking needs to be mentioned. The activities of the tobacco industry even lead to an intervention in the national parliament to stop the financing of the study. However, with a calm manner, and always a grain of humour, he won the battle. Today, smoking bans have become very common in public spaces to protect health. And, most importantly, the SAPALDIA results have certainly helped nationally and internationally to set air quality standards to protect human health.

Many of us still remember Philippe Leuenberger as a very kind, gentle, polite and intelligent man. It was always a great pleasure to meet him, and his respect and sincere interest in others stimulated all those around him. His aim was to offer service and support to patients, collaborators, students and the community. One of his favourite sentences was: "the only hierarchy that counts is that of competence". 


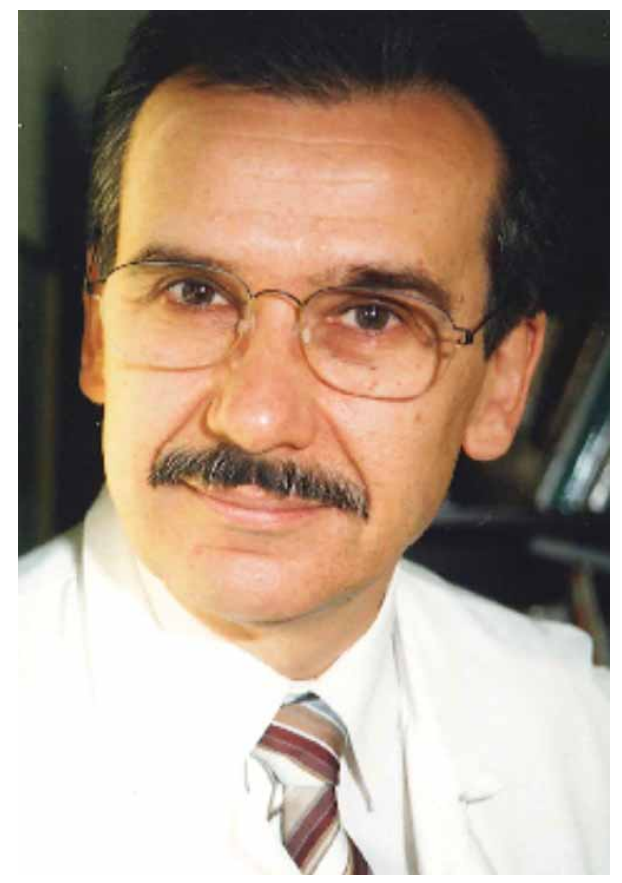

Philippe Leuenberger 1944-2015.

Philippe Leuenberger was also a passionate teacher, who among many other things developed a CD-ROM for the clinical examination of the respiratory system. He organised the European Respiratory Society annual meeting 1998 in Geneva, where he even contributed with his clarinet to the social programme.

We all are grateful for the privilege to have been able to work with Philippe Leuenberger, and proud that SAPALDIA has become an internationally recognised study, which is still ongoing, thereby keeping his memory alive. 